Supporting Information

\title{
A Multicolor Fluorescence Nanoprobe Platform using Two \\ Dimensional Metal Organic Framework Nanosheets and Double \\ Stirring Bars Assisted Target Replacement for Multiple \\ Bioanalytical Applications
}

Qian Yang ${ }^{\mathrm{a}}$, Juncheng Hong ${ }^{\mathrm{a}}$, Yong-Xiang Wu ${ }^{\mathrm{a}, *}$, Yuting Cao ${ }^{\mathrm{a}}$, Dazhen $\mathrm{Wu}^{\mathrm{a}}$, Futao $\mathrm{Hu}^{\mathrm{b}}$, Ning Gan ${ }^{\mathrm{a}, *}$

a School of Material Science and Chemical Engineering, Ningbo University, Ningbo, 315211, China.

b Faculty of Marine Science, Ningbo University, Ningbo 315211, China.

* Corresponding author:
Yong-Xiang Wu, Ning Gan
E-mail: wuyongxiang@nbu.edu.cn; ganning@nbu.edu.cn;

Tel: +86-(574)-87609987; Fax: +86-(574)-87609987 


\section{Contents}

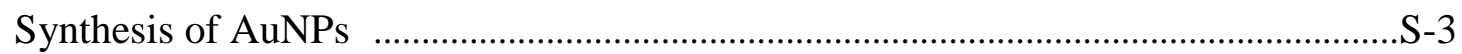

Preparation of stirring bar 1 and stirring bar 2 2.............................................................

Confocal Laser Scanning Microscope Images Study............................................... S-4

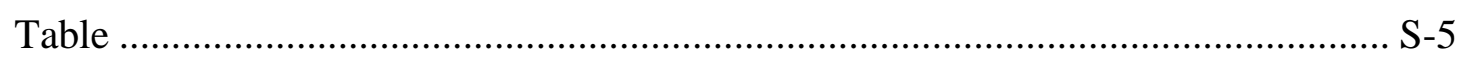

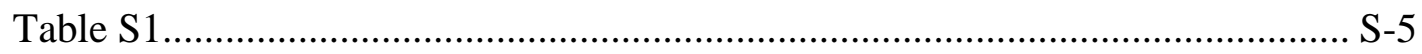

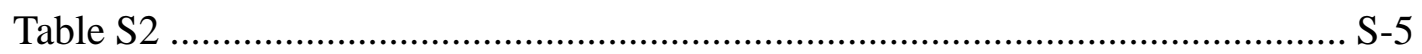

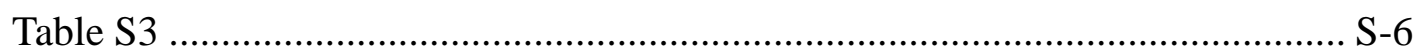

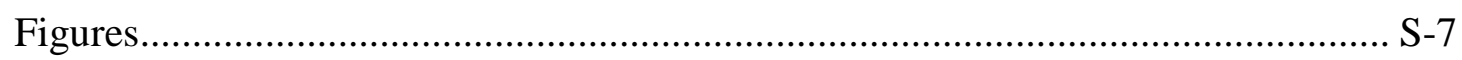

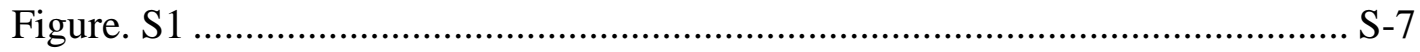

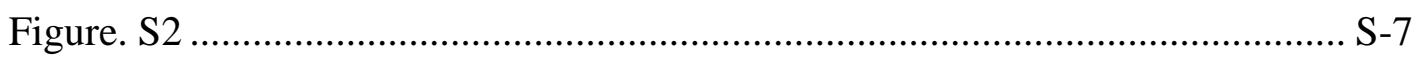

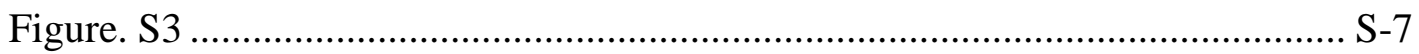

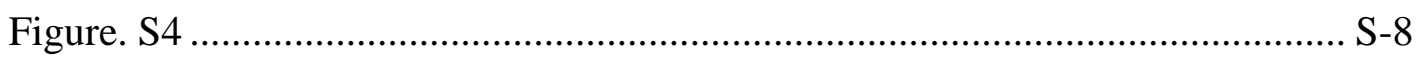

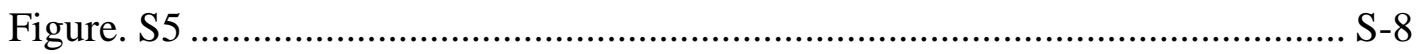

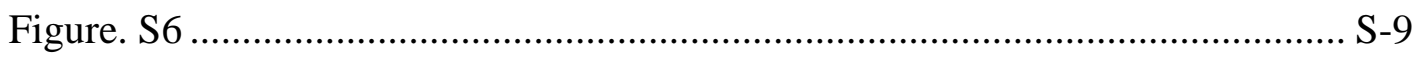

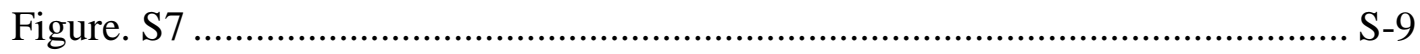

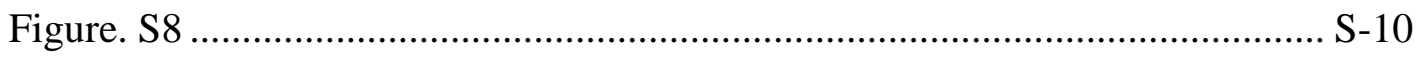

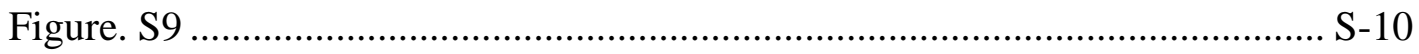

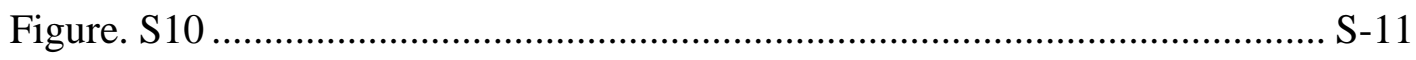

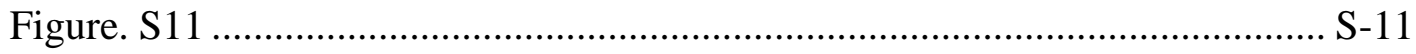

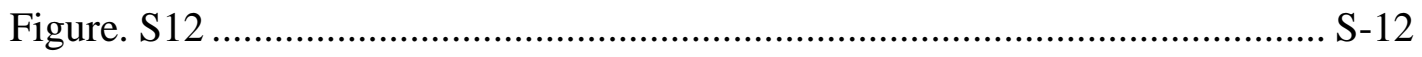

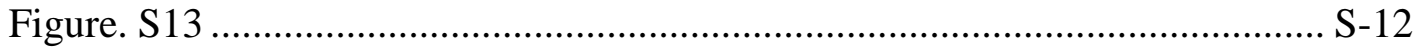

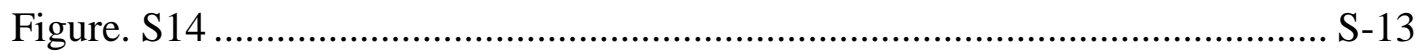

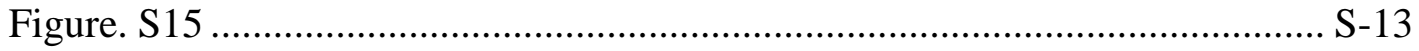

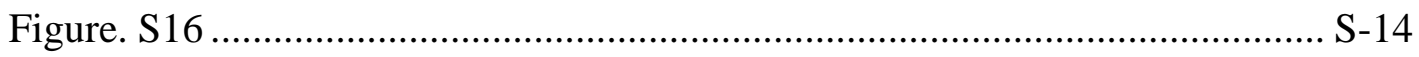

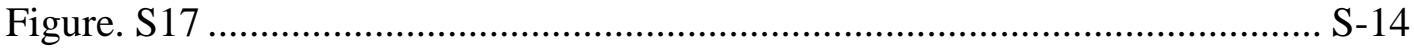

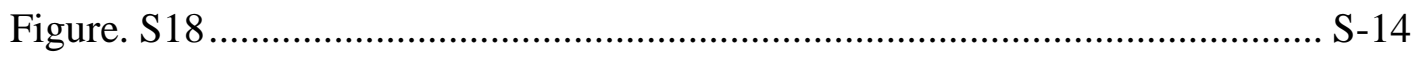

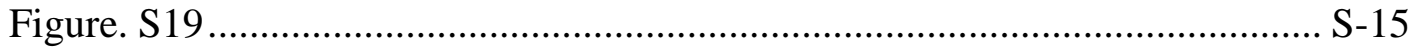




\section{Synthesis of AuNPs}

It were synthesized according to previously reported literature with some modification. In a $500 \mathrm{~mL}$ round bottom flask, $200 \mathrm{~mL}$ tetrachloroauric acid $(0.01 \%$ (w/v), $\left.\mathrm{HAuCl}_{4}\right)$ was added and heated to boiling in an oil bath with stirring. Then, $1 \%$ aqueous trisodium citrate $(5 \mathrm{~mL})$ was added quickly. After stirring for 25 minutes, the solution changed color from gray to red. After heating was stopped, the reactants were kept in the oil bath for 15 minutes. Finally, it was cooled to room temperature and then stored in an environment of $4{ }^{\circ} \mathrm{C}$. The TEM image proved that the obtained AuNPs are uniformly distributed with an average diameter of about $25 \mathrm{~nm}$.

\section{Preparation of stirring bar 1 and stirring bar 2}

Synthesis of AuNPs modified stirring bar. Electrochemical scanning with cyclic voltammetry was used to thoroughly clean stirring bars $(99.99 \%, 0.2 \mathrm{~mm}$ in diameter, $15 \mathrm{~cm}$ in length). Next, stirring bars were submerged in the MPTMS sol-gel at $25^{\circ} \mathrm{C}$ for 40 minutes. Here after, stirring bars were rinsed with deionized water several times to remove the physically adsorbed silica sol. Then, they were submerged in an AuNPs solution at $4^{\circ} \mathrm{C}$ for about 12 hours to gain an AuNPs-modified stirring bar.

Next, the thiol-modified DNA (fDNA) was diluted with TE buffer to a concentration of $100 \mu \mathrm{M}$ and stored at $4{ }^{\circ} \mathrm{C}$. Then, TCEP $(10 \mu \mathrm{M})$ treated thiol-modified DNA (fDNA) (200 $\mu \mathrm{L}, 6 \mu \mathrm{M})$ were added to PBS buffer (200 $\mu \mathrm{L})$. AuNPs modified stirring bar was immersed in the mixture at $4^{\circ} \mathrm{C}$ for approximately 12 hours. Finally, the stirring bar was thoroughly washed with deionized water to remove unreacted DNA. The gold-labeled primer-functionalized stirring bar we obtained was stored in PBS 
buffer saline at $4{ }^{\circ} \mathrm{C}$. G-2 was prepared in the same way as above, and we modified the fuel chain thereon. Finally, G1 was immersed in a solution containing 25 nM aDNA1, aDNA2, aDNA3, cDNA1, cDNA2 and cDNA3 for 2 hours.

\section{Confocal Laser Scanning Microscope Images Study.}

The fish tissue was soaked for 1 hour in the solution containing antibiotics (10 $\mathrm{nM}$ ), the antibiotic was absorbed by fish tissue, so antibiotics were present in the tissue sections of fish. The fish tissue slices were placed in a mixed solution containing $40 \mu \mathrm{L}$ P1 $(1.0 \mu \mathrm{M}), 40 \mu \mathrm{L} \mathrm{P} 2(1.0 \mu \mathrm{M})$ and $40 \mu \mathrm{L}$ P3 $(1.0 \mu \mathrm{M})$. Two stirring bars were reacted with targets for $30 \mathrm{~min}$. After Y-DNA and fuel chain on stirring bar were reacted with targets, stirring bars were taken out and obtaining a supernatant. Then Cu-TCPP nanosheets (30 $\mu \mathrm{g} \mathrm{mL}^{-1}$ ) was added to the reaction system and incubated for 5 minutes. The fish tissue slices be taken out and washed 5-6 times by PBS solution. At last, the prepared fish tissue slices were observed with a confocal microscope. The excitation wavelengths were $494 \mathrm{~nm}$ (FAM), $588 \mathrm{~nm}$ (ROX) and $650 \mathrm{~nm}(\mathrm{Cy} 5)$, respectively. The fluorescence emission wavelength range were 510-600 nm(FAM), 600-650 nm(ROX) and 650-720 nm (Cy5), respectively. 
Table S1. The sequence oligonucleotides used in this strategy.

\begin{tabular}{|c|c|}
\hline Name & Sequence $\left(5^{\prime}-3^{\prime}\right)$ \\
\hline Captured DNA1 (cDNA1) & $\begin{array}{l}\text { ACT TCA GTG AGT TGT CCC ACG GTC GGC GAG TCG GTG } \\
\text { GTA GCC TAT GCA GTT T (CAP) }\end{array}$ \\
\hline Captured DNA2 (cDNA2) & $\begin{array}{l}\text { ACG TTG ACG CTG GTG CCC GGT TGT GGT GCG AGT GTT } \\
\text { GTG TCC TAT GCA GTT T (OTC) }\end{array}$ \\
\hline Captured DNA3 (cDNA3) & $\begin{array}{l}\text { AGA TGG GGG TTG AGG CTA AGC CGACC TAT GCA GTT T } \\
\text { (KANA) }\end{array}$ \\
\hline Assisted DNA1 (aDNA1) & TTT CGC TGT GAC CTA CCA CCG ACT GCA CAC AG \\
\hline Assisted DNA2 (aDNA2) & TTT CGC TGT GAC ACA CAA CAC TCG GTG GCC AT \\
\hline Assisted DNA3 (aDNA3) & TTT CGC TGT GAC TCG GCT TAG CCT CAT TGA AC \\
\hline Fixed DNA1 (fDNA) & AGA AGA TTT GTG CAT AGG GTC ACA G-SH \\
\hline Replace DNA1 (S1) & $\begin{array}{l}\text { GGA TAC CTT GAC GCT ACC ACC GAC TCG CCG ACC GTG } \\
\text { GGA CAA CTC ACT GAA GT-SH }\end{array}$ \\
\hline Replace DNA2 (S2) & $\begin{array}{l}\text { GGA TAC ACA CAA CAC TCC CAC CAC AAC CGG GCA CCA } \\
\text { GCG TCA ACG TTC TAA TT-SH }\end{array}$ \\
\hline Replace DNA3 (S3) & $\begin{array}{l}\text { GGA TAC TCG GCT TAG CCT CAA CCC CCA TCT TCC TTA } \\
\text { A-SH }\end{array}$ \\
\hline Signal probe1 (P1) & CT GTG TGC AGT CGG TGG TAG GTC ACA-FAM \\
\hline Signal probe2 (P2) & AT GGC CAC CGA GTG TTG TGT GTC ACA-ROX \\
\hline Signal probe3 (P3) & GT TCA ATG AGG CTA AGC CGA GAC ACA-Cy5 \\
\hline
\end{tabular}

Note: The red section sequences were the target's aptamer nucleotides.

Table S2. The developed method and ELISA method for detect CAP, OTC and KANA.

\begin{tabular}{|c|c|c|c|c|c|}
\hline Sample & Targets & $\begin{array}{c}\text { Blank } \\
(\mathrm{nM})\end{array}$ & Added (nM) & Detection (nM) & ELISA (nM) \\
\hline \multirow{6}{*}{ Milk } & \multirow{2}{*}{ CAP } & \multirow{2}{*}{0.65} & 0.03 & $0.69 \pm 0.01$ & ND \\
\hline & & & 3.00 & $3.68 \pm 0.02$ & $3.63 \pm 0.03$ \\
\hline & \multirow{2}{*}{ OTC } & \multirow{2}{*}{0.52} & 0.03 & $0.53 \pm 0.02$ & ND \\
\hline & & & 3.00 & $3.52 \pm 0.01$ & $3.52 \pm 0.01$ \\
\hline & \multirow{2}{*}{ KANA } & \multirow{2}{*}{0.91} & 0.03 & $0.92 \pm 0.03$ & ND \\
\hline & & & 3.00 & $3.92 \pm 0.04$ & $3.91 \pm 0.03$ \\
\hline \multirow{6}{*}{ Fish } & \multirow{2}{*}{ CAP } & \multirow{2}{*}{0.35} & 0.03 & $0.38 \pm 0.01$ & ND \\
\hline & & & 3.00 & $3.35 \pm 0.02$ & $3.40 \pm 0.03$ \\
\hline & \multirow{2}{*}{ OTC } & \multirow{2}{*}{0.93} & 0.03 & $0.95 \pm 0.02$ & ND \\
\hline & & & 3.00 & $3.92 \pm 0.01$ & $3.92 \pm 0.01$ \\
\hline & \multirow{2}{*}{ KANA } & \multirow{2}{*}{0.11} & 0.03 & $0.14 \pm 0.03$ & ND \\
\hline & & & 3.00 & $3.12 \pm 0.04$ & $3.06 \pm 0.03$ \\
\hline
\end{tabular}

ND: Not Detected.

Table S3. Recovery results for CAP, OTC and KANA. 


\begin{tabular}{ccccc}
\hline Targets & Added (nM) & Detection (nM) & $\begin{array}{c}\text { RSD (\%) } \\
(\mathrm{n}=7)\end{array}$ & Recovery (\%) \\
\hline CAP & 0.100 & $0.110 \pm 0.003$ & 3.0 & 110 \\
CAP & 1.000 & $0.990 \pm 0.034$ & 3.5 & 99.6 \\
OTC & 0.100 & $0.101 \pm 0.003$ & 2.7 & 103 \\
OTC & 1.000 & $1.03 \pm 0.024$ & 2.4 & 103 \\
KANA & 0.100 & $0.101 \pm 0.004$ & 4.1 & 102 \\
KANA & 1.000 & $0.970 \pm 0.021$ & 2.2 & 97.9 \\
\hline
\end{tabular}




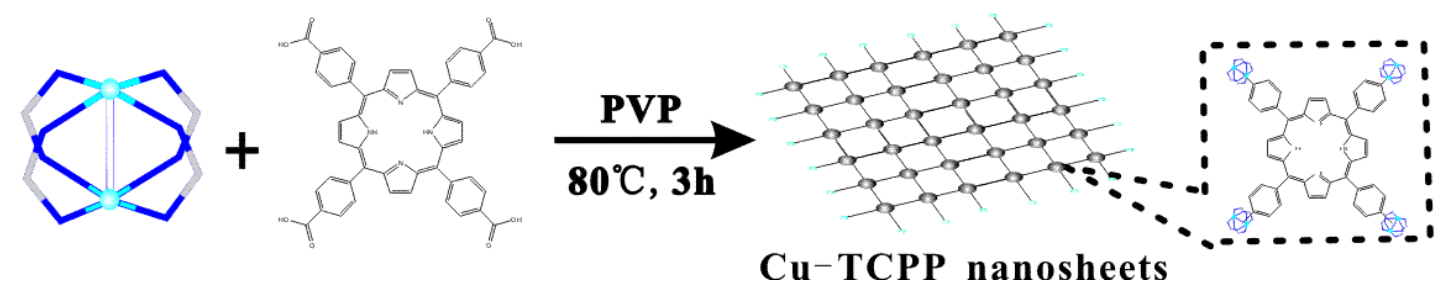

Figure. S1. Schematic diagram of Cu-TCPP nanosheets synthesis.

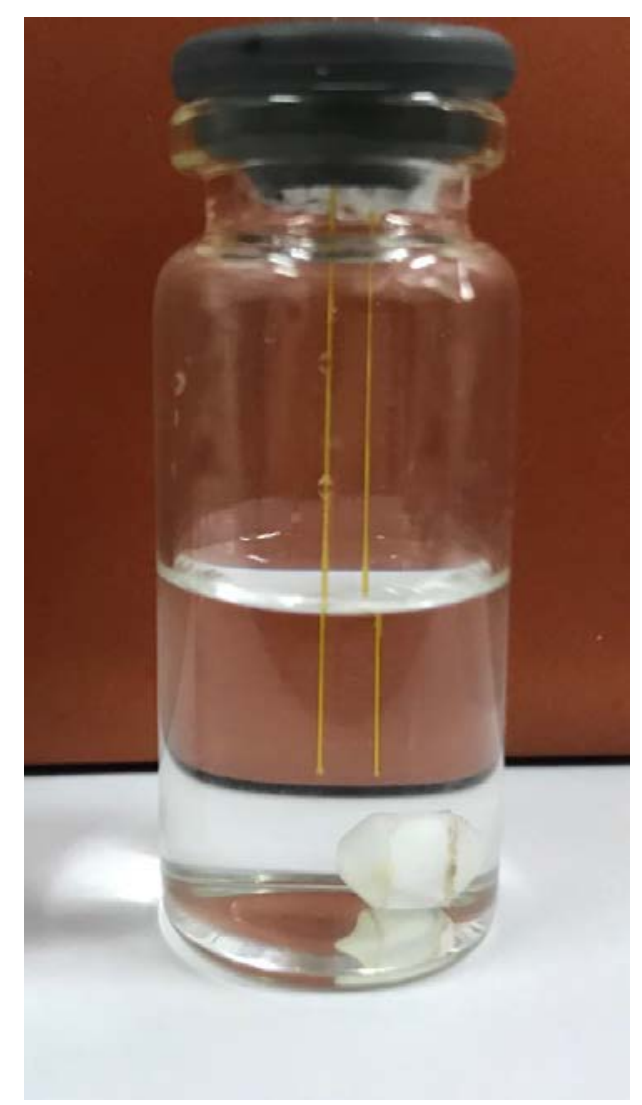

Figure. S2. The photo of double stir-bars assisted target recycling system.

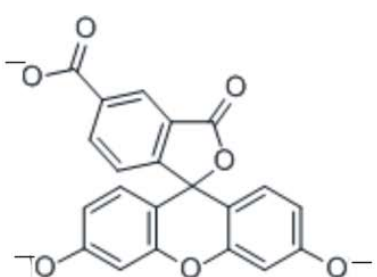

FAM

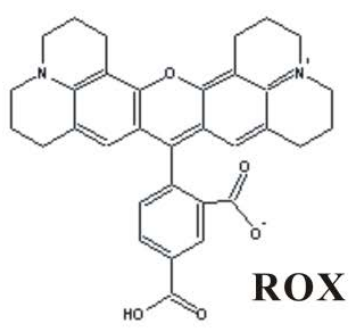

ROX

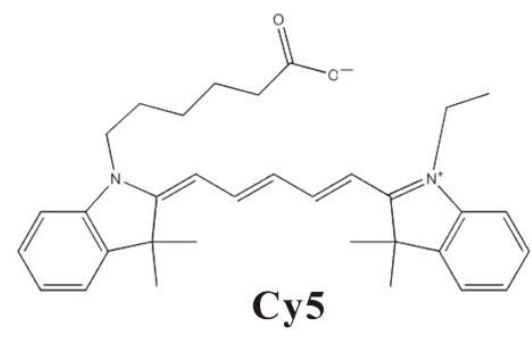

Cy5

Figure. S3. The structural formula of FAM, ROX and Cy5. 

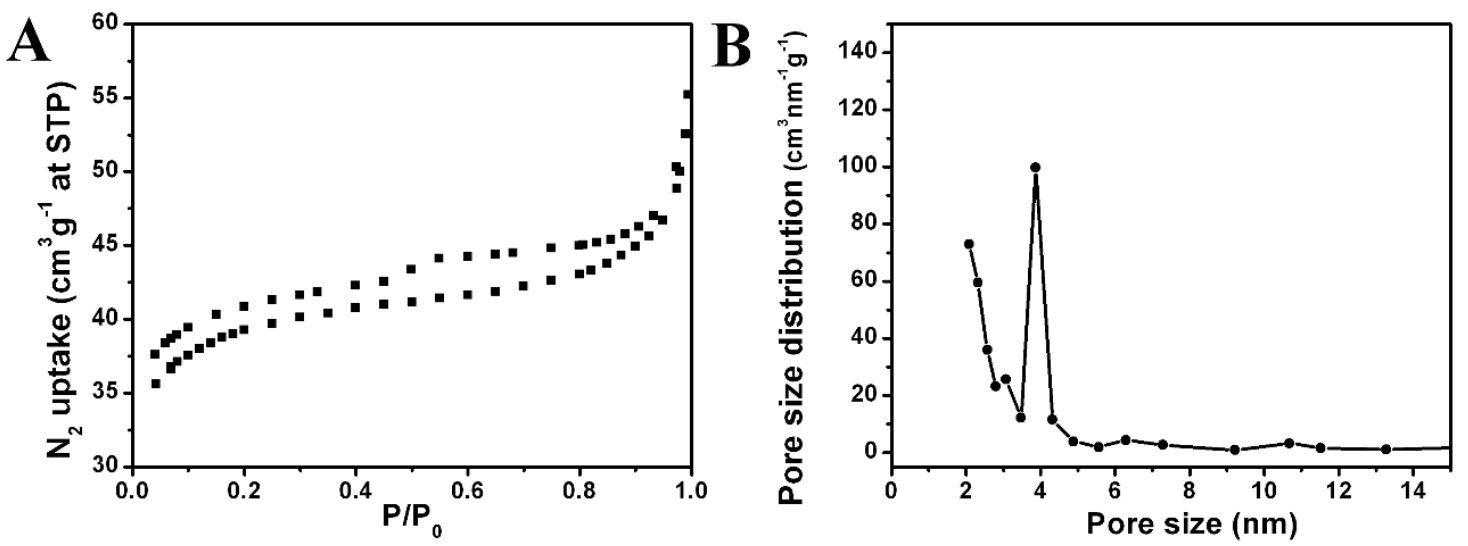

Figure. S4. (A) $\mathrm{N}_{2}$ adsorption-desorption isotherms of $\mathrm{Cu}-\mathrm{TCPP}$ nanosheets. (B)

Corresponding pore-size distribution curves of Cu-TCPP nanosheets.

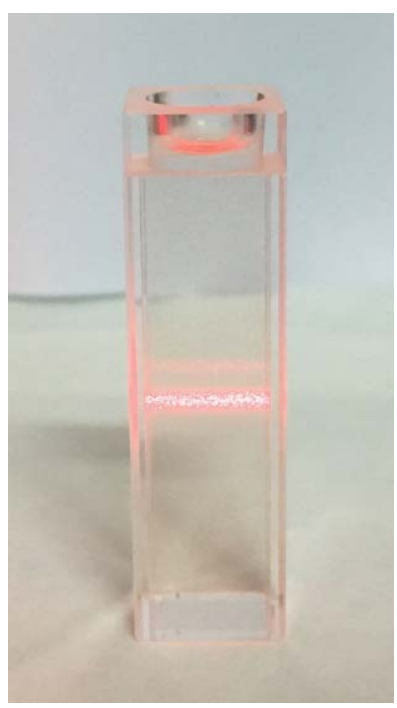

Figure. S5. The Tyndall Effect of Cu-TCPP nanosheets. 


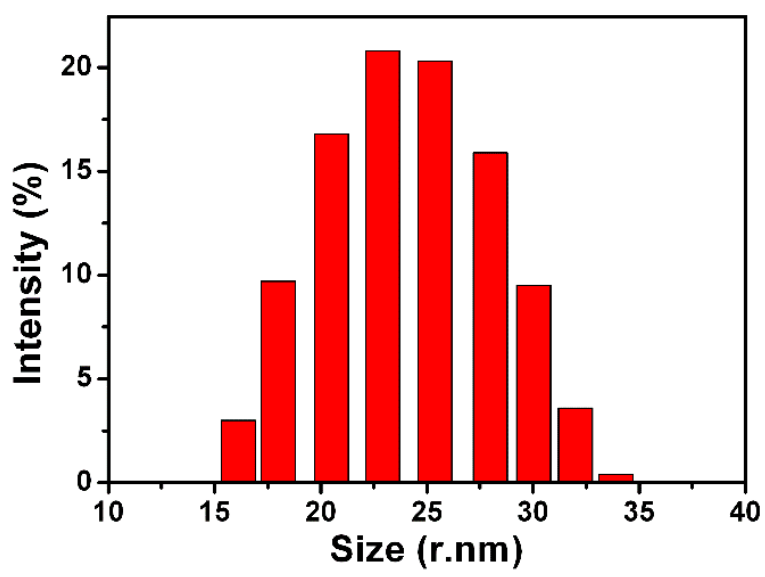

Figure. S6. Dynamic light scattering (DSL) of the prepared AuNPs.

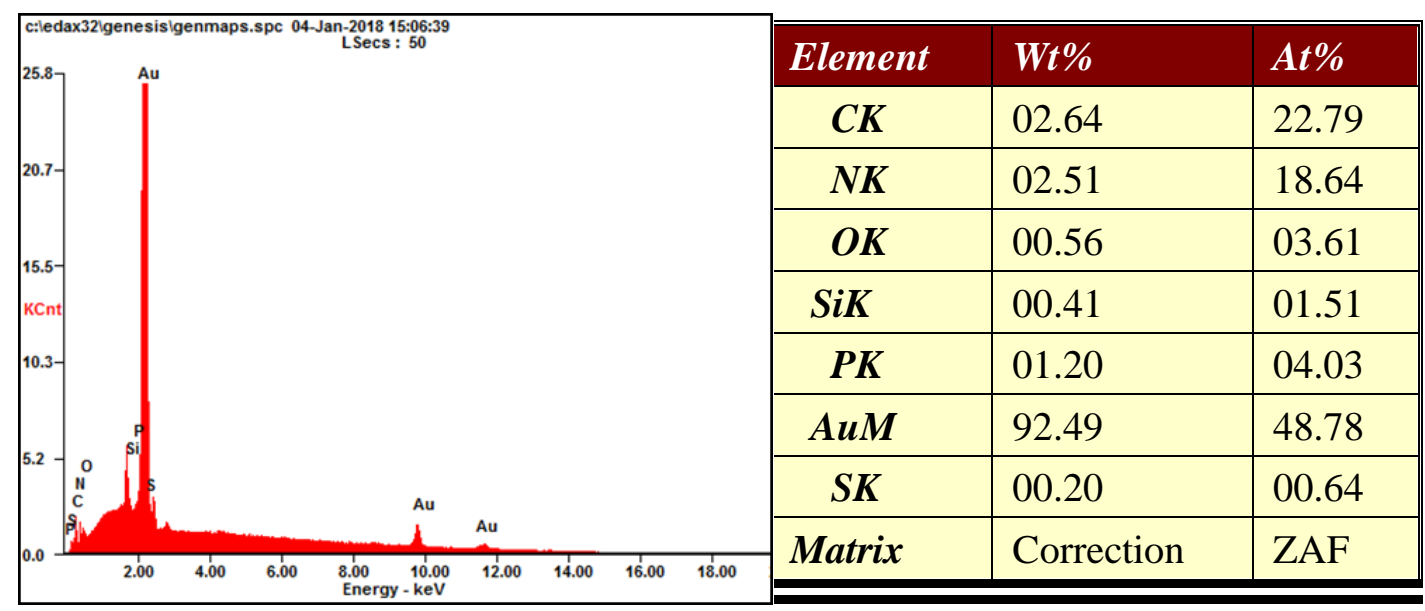

Figure. S7. The EDX of gold bar was modified with gold-labeled primer. 


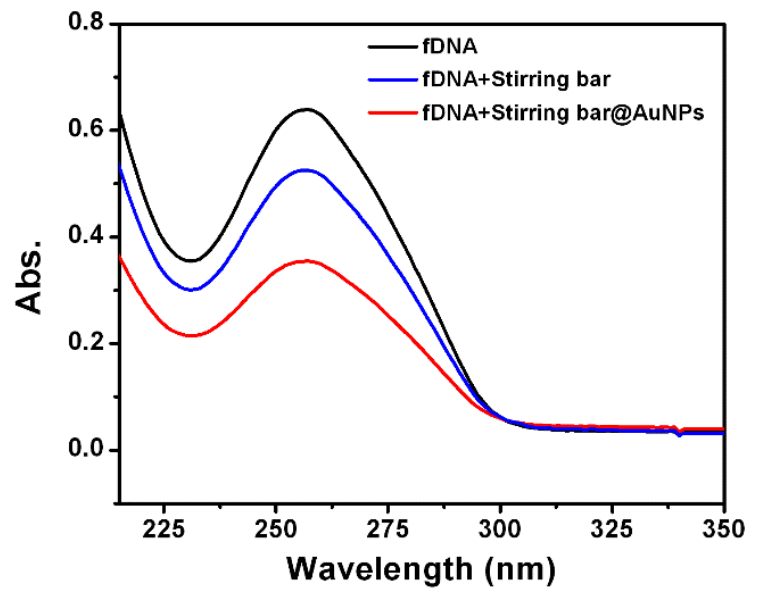

Figure. S8. The UV-vis absorption spectra of fDNA (3 $\mu \mathrm{M})$.

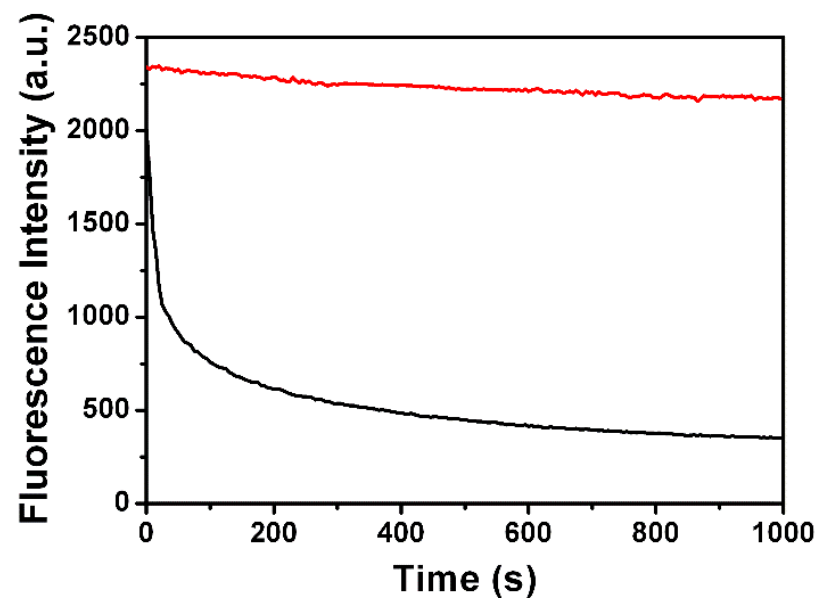

Figure. S9. Fluorescence quenching under $\lambda_{\mathrm{ex}}=588 \mathrm{~nm}$ of P2 $(10 \mathrm{nM})$ with $\mathrm{Cu}-\mathrm{TCPP}$ nanosheets (black) and without $\mathrm{Cu}-\mathrm{TCPP}$ nanosheets (red). 


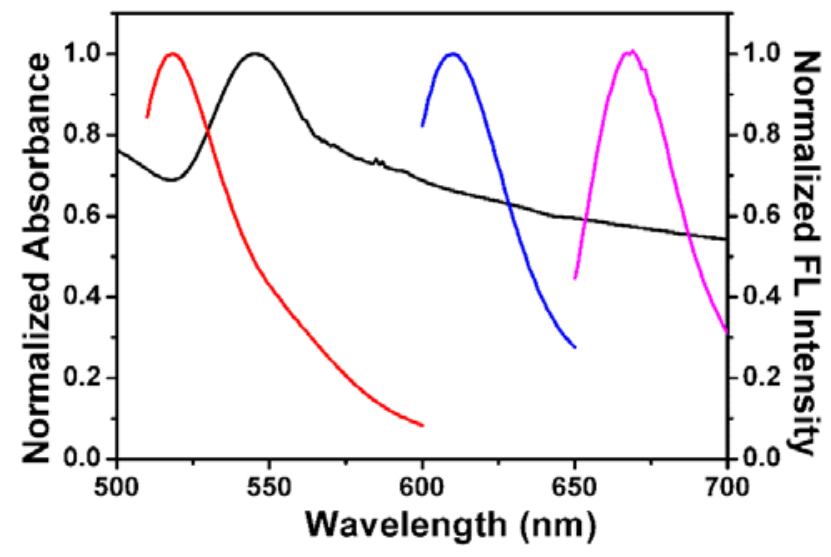

Figure. S10. The UV-vis absorption spectrum of Cu-TCPP nanosheets (black), and the fluorescence spectra of FAM (red), ROX (blue), Cy5. (pink).
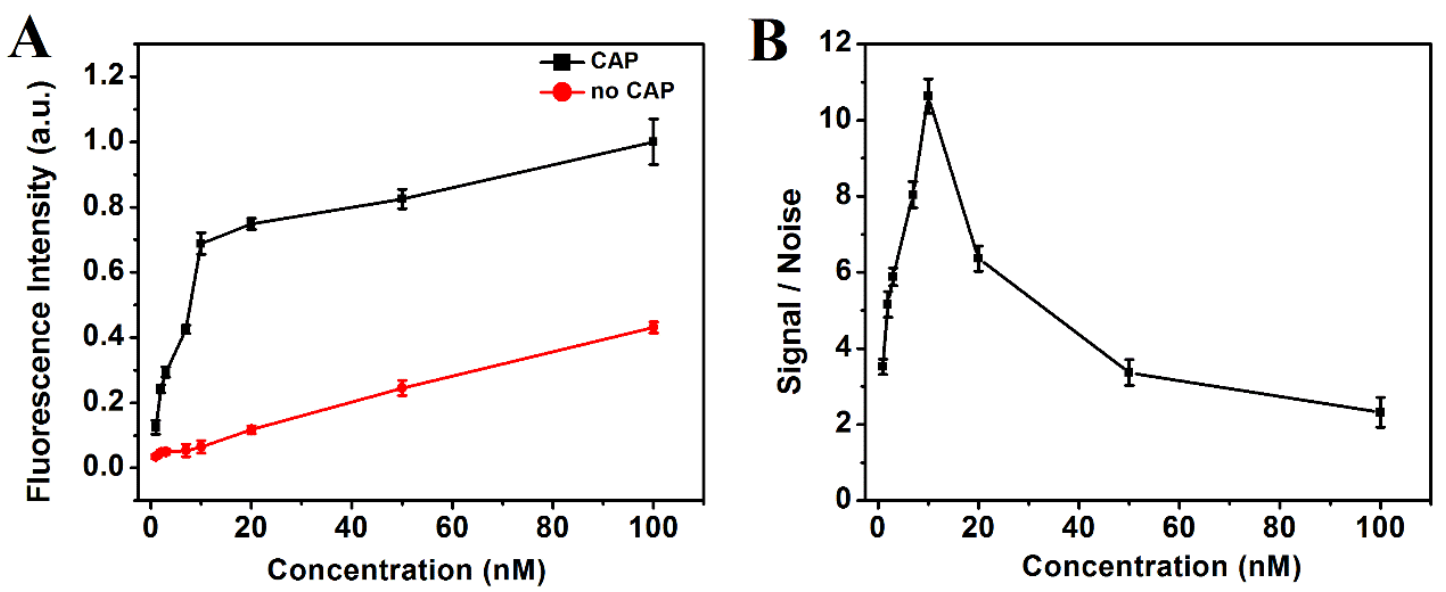

Figure. S11. (A) The fluorescence intensity of the detection system with different concentration of probe in the presence of $10 \mathrm{nM}$ CAP (black) and in the absence of CAP (red); (B) There are signal to noise ratios for different probe concentrations. 

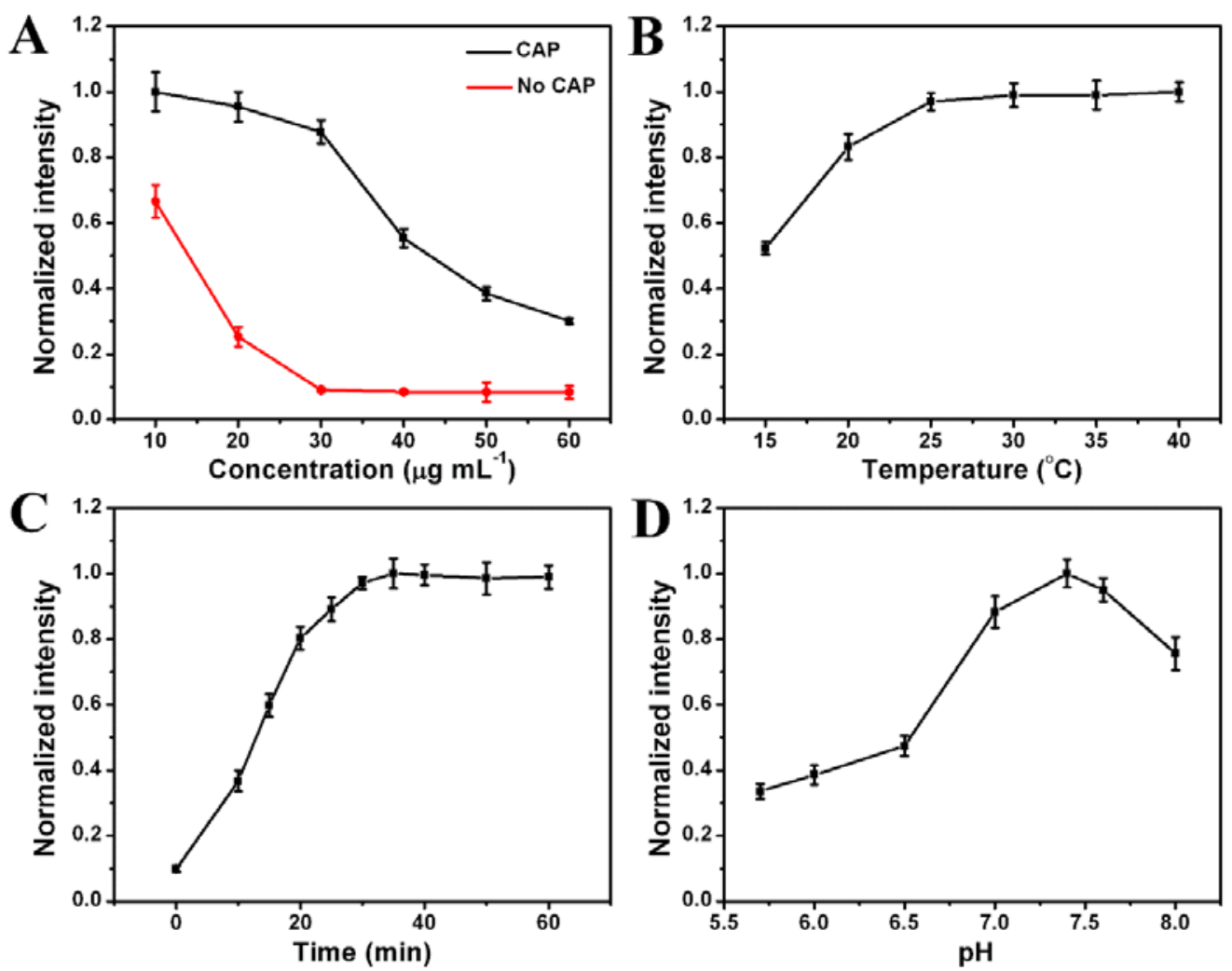

Figure. S12. (A) The effect of Cu-TCPP nanosheets concentration of this assay; (B) the optimization of reaction temperature $\left(15^{\circ} \mathrm{C}, 20^{\circ} \mathrm{C}, 25^{\circ} \mathrm{C}, 30^{\circ} \mathrm{C}, 35^{\circ} \mathrm{C}, 40^{\circ} \mathrm{C}\right)$; (C) the optimization of reaction time; (D) the optimization of $\mathrm{pH}(5.7,6.0,6.5,7.0,7.4,7.6,8.0)$, using OTC as an example.

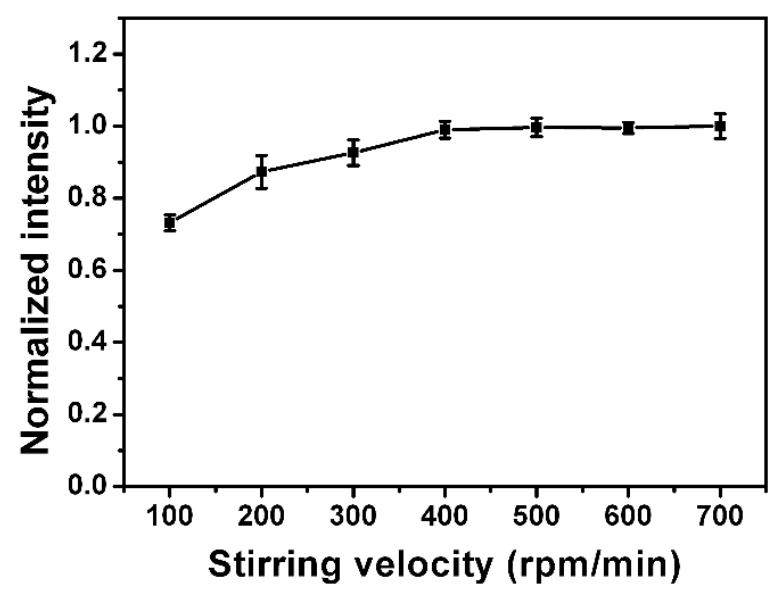

Figure. S13. The optimization of stirring velocity. 


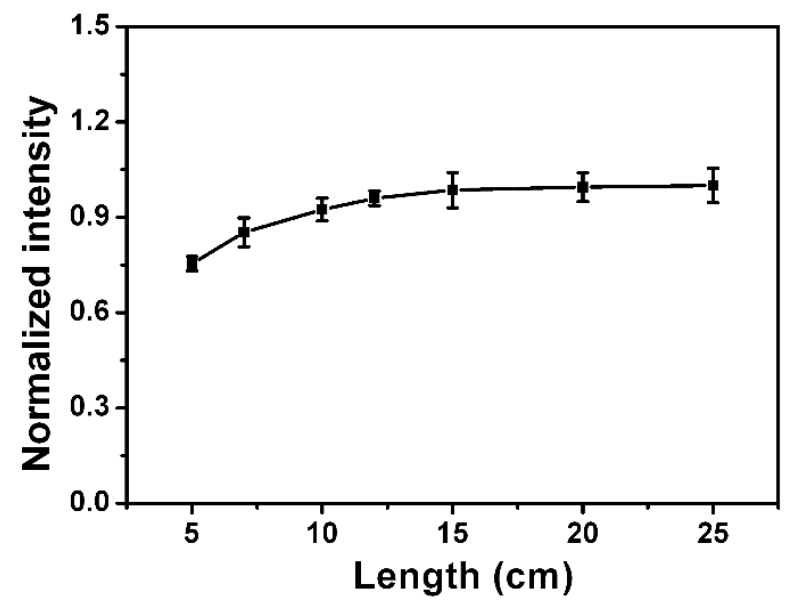

Figure. S14. The optimization of gold bar's length with 30 nM KANA.

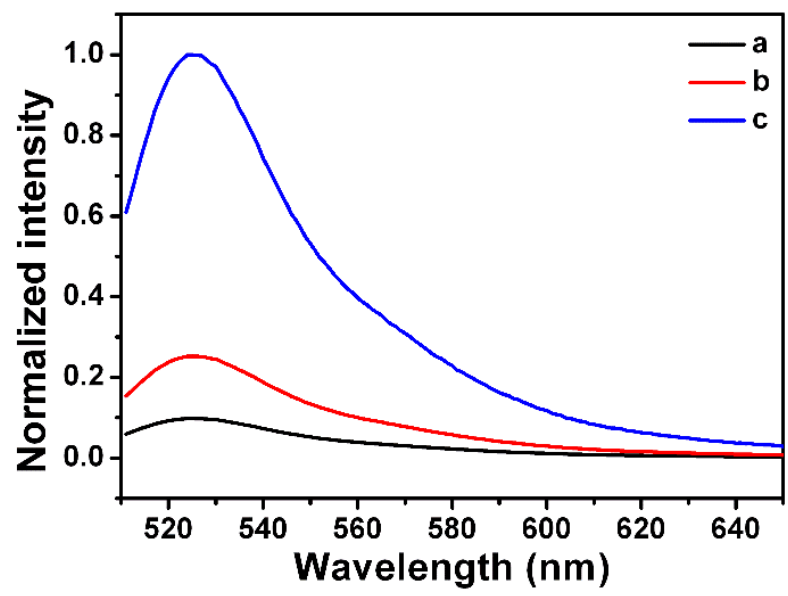

Figure. S15. The feasibility of dSB-TMSDR: (a) bar 1/bar 2, (b) bar 1, CAP (20 nM), (c) bar 1/bar 2, CAP (20 nM). In the above experiments, both the signal probe (1 nM) and $\mathrm{Cu}$-TCPP nanosheet were present in the reaction solution. 


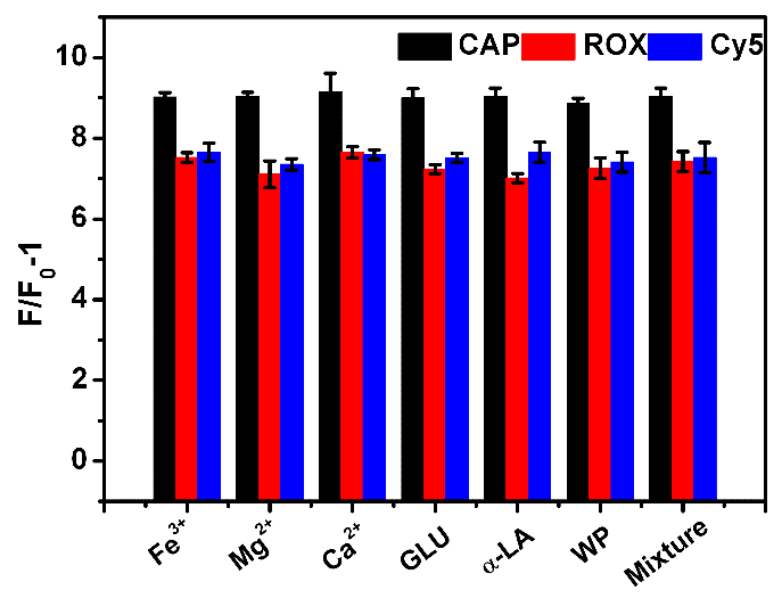

Figure. S16. The interference experiment of the sensing platform towards several proteins and common metal ions.

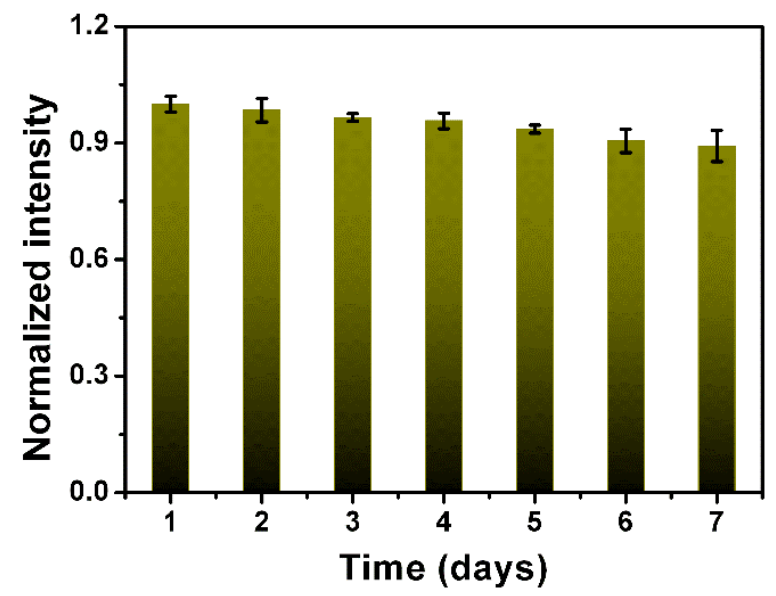

Figure. S17. The stability of this biosensor system.

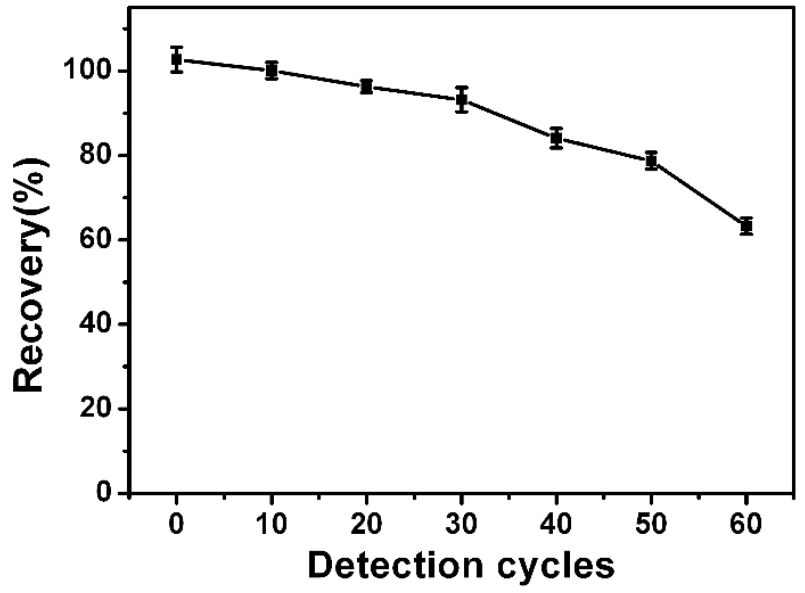

Figure. S18. The stirring bar used in this strategy. 


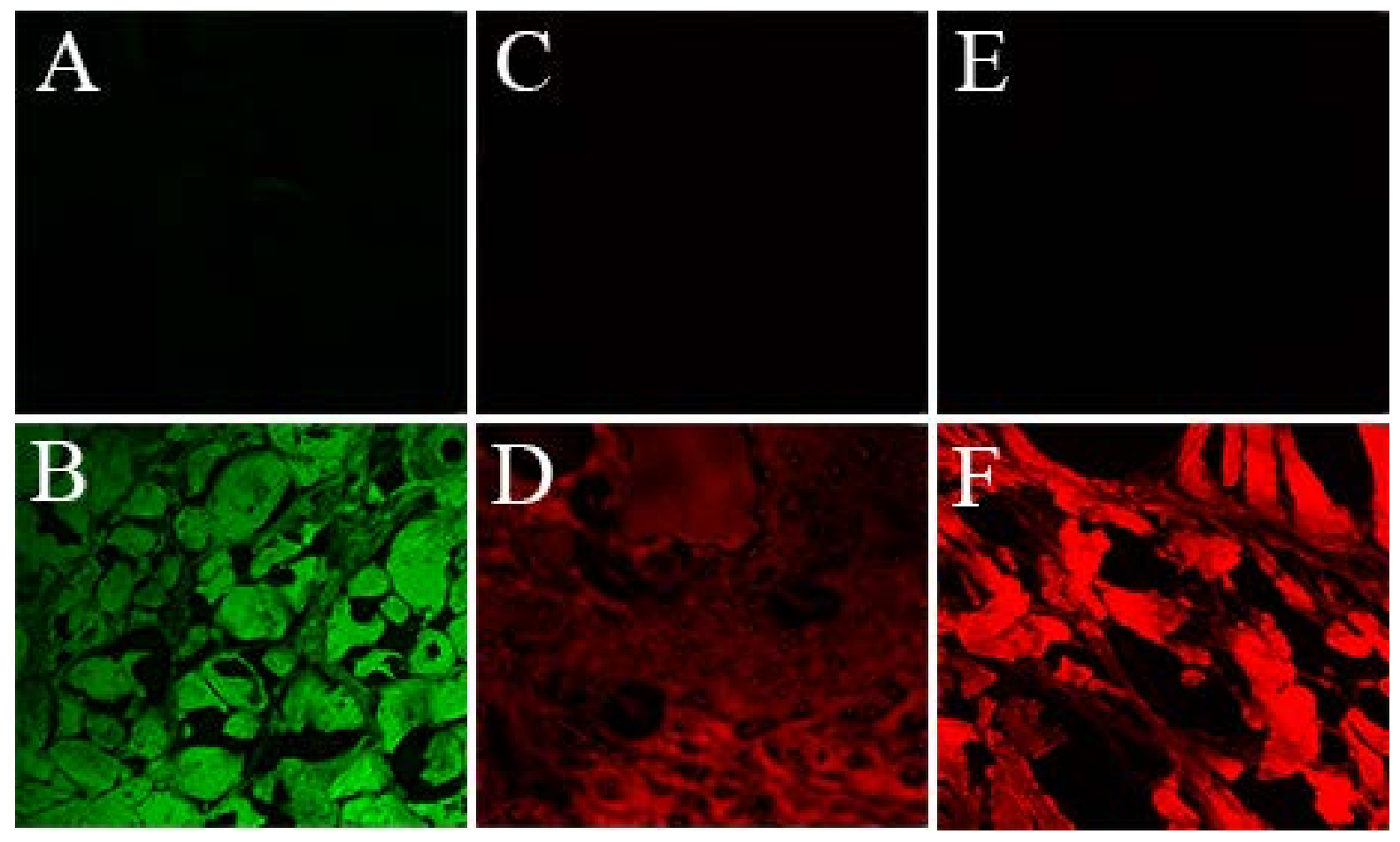

Figure. S19. Confocal fluorescence images treated with nanoprobe of fish tissue slices in the absence (A) or presence (B) of CAP, absence (C) or presence (D) of OTC, and absence (E) or presence (F) of KANA. 